It gives me great pleasure to be able to accept your paper for publication in Journal of Further and Higher Education. We are pleased to accept your paper in its current form which will now be forwarded to the publisher for copy editing and typesetting. Oct 2013

\title{
Living and learning as an international postgraduate student at a Midlands
} University

Hugh Busher*, Gareth Lewis, Chris Comber, University of Leicester, School of Education

*Corresponding author

*Hugh Busher, School of Education, University of Leicester, 21 University Road Leicester, LE1 7RF, UK t: 0116252 3688; e: hugh.busher@ le.ac.uk

Chris Comber, School of Education, University of Leicester, 21 University Road Leicester, LE1 7RF, UK t: 0116252 3688; e: cjfc1@le.ac.uk Gareth Lewis, School of Education, University of Leicester, 21 University Road Leicester, LE1 7RF, UK t: 0116252 3688; e: gl78@ le.ac.uk 


\begin{abstract}
This paper investigates the views of 20 full-time international postgraduate students, many of whom were Chinese, on living, learning and becoming successful students at one university in a multi-cultural city in the Midlands of England. The qualitative study built on findings from the International Students' Barometer (ISB) survey for the university, in that it seeks to understand how students experience of context (living) interacted with their experience of learning in building their identities as successful learners. Student participants were sampled opportunistically within a purposive framework. Data, was collected through audio-recorded individual semi-structured interviews, using as a stimulus participant-constructed concept maps of their perceptions of learning in the university and living in the city. Interview data were transcribed and analysed thematically. Main findings showed that participants enjoyed living in a city with an international culture, although some found it strange initially, because they encountered different styles of life and food, including some that they enjoyed at home. They welcomed studying at the university with a high international prestige, a wide range of excellent facilities and generally approachable tutors but were shocked by having to undertake unfamiliar styles of independent learning with brief teaching hours. They perceived culture shock as transitional which declined as they made friends, often with co-linguists, and became familiar with life in the city, work in the university and the extensive support of tutors.
\end{abstract}

Keywords: Culture shock, identity shifts, cultural contexts, international students 


\section{Introduction}

Becoming a student in an unfamiliar university often involves people changing their approaches to learning and sometimes their discipline/major from their first degree. All students face issues around accommodation, financial and work routines to manage alongside their learning and social aspects of life. However, full-time international postgraduate students study and live in a country and culture that is not their own, often working in their second or third language. Further they have to work with people with different cultural perceptions from their own, in unfamiliar social and academic contexts, on courses with unfamiliar structures, rubrics, and cultures about learning. Yet, to be successful in their studies, they need to retain and develop positive self identities as successful learners.

The International Students' Learning Investigation (ISLI) focused on how some international postgraduate students studying on taught Masters courses at one university in a multi-cultural city in the Midlands of England constructed and enacted their understandings of what it means to be a successful student and how tutors and administrators can facilitate that. The study takes the view that people's social interactions are major mediators of learning processes (Vygotsky 1978) so that students' views of themselves as learners are strongly affected by the relationships they build with other people and their perceptions of the institutional and social processes within which their learning is situated. Access to the institutional and learning processes are often controlled by powerful gatekeepers, such as tutors in a university, whose actions international students may not fully understand (Bourdieu, Passeron and St Martin 1994). However, the study goes beyond that of Bourdieu, Passeron and St Martin (1994), which investigated how students in a French university adapted to their learning environments, by investigating how international students' relationships with their civic environment as well as their academic environment affects their identities, causing what is sometimes called 'culture shock'(Furnham and Bochner in La Brack 2002) or 'adjustment difficulties' because, initially, 'international students are not aware of the implicit social rules that regulate interaction in the host country' (Chapdelaine and Alexitch, 2004, 167). This affects international students' adaptation to becoming successful students in an initially unfamiliar university. 
This paper considers international students' views of how they adapted to living and learning in strange cultures and how this was affected by their histories and the working and social environments in which they found themselves.

\section{Conceptual framework}

Adapting to the strange environments of an unfamiliar city and university is a major undertaking for any postgraduate student but this is exacerbated when a student is having to work in a language that is not their own and is experiencing academic and civic cultures and practices that do not map easily on to their prior experiences. This may make problematic their reading of the overt and covert practices and discourses of the institution in which they are studying, leading to potential misunderstandings, for example of course requirements or tutors' intentions. This may lead to students inhibiting their learning without their tutors even being aware that they do so.

The construction of identity is an on-going project (Giddens 1991) linking people's histories to their developing interactions with the other people and institutional structures in which they are placed (Busher 2005a \& b) in particular socio-economic and political contexts. For all students a new university represents a liminal space (Bhabha 1994), a zone of transition in which to build new cultures with different people in initially strange environments. For international students in the liminal spaces of foreign universities the construction of identity is complex (Zhen 2009; Lei 2010; Li 2011) drawing on an ongoing process of 'negotiation and mediation with the surrounding environment, selfanalysis...self-reflection and self-reorientation' (Gu, Schweisfurth and Day 2010). Further the challenges facing them are not just cultural but also linguistic. Language proficiency is crucial for both academic and social integration (Copland and Garton 2011) but there is no clear indication of what level of proficiency, e.g. as measured by IELTS scores, is good enough.

Key challenges for international students are perceived to be differences in teaching styles, curricular approaches and evaluation methods they encounter in the Western academy compared with those in their own education systems (Gonçalves 2011). Socially they are thought to experience considerable tensions, too, these being feelings of isolation 
- or what Sawir et al. (2008) refer to as 'cultural loneliness' - because of unfamiliar social conventions/mores and difficulties in making cross-cultural friendships (Pritchard and Skinner 2002; Chapdelaine and Alexitch 2004). Moreover for the majority of international students, these issues are set within an unfamiliar linguistic context, increasing the level of challenge for both social and educational interaction (Mulligan and Kirkpatrick 2000; Zhang and Mi 2010).

Processes of adaptation by international students can be represented in various ways. The concept of 'culture shock' is seen as:

[an] unpleasant and unexpected realisation of the extent of the differences between cultures, leading to an unsettling re-evaluation of one's own culture (Wu and Hammond 2011, 425)

This idea is often invoked to describe the first stages of international students' integration into a socio-economic and institutional culture different to one with which they are familiar (Lysgaard 1995). Chen, (2007) suggests that the experience of most students is more 'bump' than trauma. Moreover, Gu et al. $(2010,19)$ found that these early unsettling experiences are predominantly related to academic, rather than social culture, and act as a catalyst in a complex process of 'transition and transformation' - the re-evaluation to which Wu and Hammond (2011) refer - in which students are proactive in the construction of 'identity, agency and resilience'.

How higher education institutions interpret and respond to the social and learning needs of their international students is of some importance (Andrade and Young 2006) if appropriate academic and social support is to be provided. For example, perceptions by tutors in the Western academy of East Asian students' experiences are mixed. Positively, they are perceived as high achievers, diligent, hard working, respectful, good attendees, but more negatively they are perceived as uncritical, reluctant to challenge, ask question or contribute to discussions; unfamiliar with group work, rote learning (Volet and Renshaw 1999; Barron 2003; Barron et al. 2010). However, positive student interactions and collaborative activities help international students foster intercultural competence (Webb and Palinscar 1996; Sam 2001; Dixon et al. 2007). 


\section{Research design and methodology}

The International Students' Learning Inquiry (ISLI) was a qualitative cross-sectional study based in one university in a multi-cultural city in the Midlands of England. It drew on a social interactionist perspective to investigate in more depth some of the findings for the university presented by the International Students' Barometer (ISB) survey. The findings of the ISB allowed the project team to identify key variables for international students - learning satisfaction, living satisfaction, support satisfaction. These were followed up in more depth through one-to-one interviews to clarify what international postgraduate students thought about being and becoming successful students whilst living in specific contexts of City and University. It also helped the researchers to identify which ethnic groups of full-time international students tended either to strongly enjoy or dislike their experiences, indicating from which groups of students to select people for interview. For this reason the study selected Mainland Chinese students (a more or less neutral view of the University), Hong Kong Chinese students (with strongly negative views), and Pakistani students (with strongly positive views).

During the latter part of the Spring term in a Midlands University in England, the study recruited 25 full-time international postgraduate students undertaking taught Masters degree, 15 of whom were Mainland Chinese (all female) and ten (male and female) from various other countries. These participants were interviewed individually by the project's volunteer research assistants who were themselves predominantly Mainland Chinese postgraduate students. It was hoped that the reduction in social distance between interviewers and interviewees would help interviewees to fell more relaxed and willing to be open about their experiences.

The timing of the research interviews meant that students' perceptions of their early days in the City and University were already part of their histories, rather than reflections on current experiences. However, these recollections can be quite accurate (Goodson and Numan 2002) and trustworthy. To have avoided this problem the project would have had to have carried out interviews in the early Autumn term of the academic year as well as in the later Spring term but this was not possible. Part of the intention of the project was to give volunteer international postgraduate students experience of carrying out empirical research that would make an original contribution to knowledge and benefit others, after they had completed a 
research methods module on their Master's degree course but before they began their dissertations.

As it proved to be very difficult to contact Pakistani postgraduate students and Hong Kong Chinese postgraduate students because they were spread much more thinly across the University's departments than were Mainland Chinese postgraduate students, other international postgraduate students who volunteered were accepted as participants. Unfortunately, for some of these it proved impossible to find a convenient time for them to be interviewed.

Before each 30 minute semi-structured interview, using the questions shown below, was audio-recorded, participants were asked to draw two concept maps (Borthwick 2011) as visual representations of themselves working in the University and living in the City, drawing on the ideas of Wall and Higgins (2009). They were allowed to label these visual representations. Although the main intention was to use the concept maps as triggers or prompts for the interviews, the researchers recognised they provided useful visual data in themselves of how the international students constructed their relationships with the City and the University.

\section{Interview questions}

- What have been your previous experiences of Higher Education

- How do your previous experiences differ from those here?

- Why choose this City and University?

- What is it like to live in [City]?

- What practices in learning at [University] do you welcome?

- What barriers to learning, whether socio-cultural, pedagogic, linguistic or curricula, do you think you encounter?

- What support do you have at [University]?

- How do you perceive your relationships with your tutors and the University?

- Evaluate your experiences at [University]

- What advice would you give to prospective students and University staff 
The data from the transcribed interviews was analysed thematically. Unfortunately, in the transcription process, five interviews, one Mainland Chinese and four others, became corrupted and unusable, leaving the study with usable data from only 20 participants' interviews. The concept maps were analysed hermeneutically using a grounded theory approach of description leading to analysis of each concept map before these interpretations were compared across concept maps. This approach took account of the views of Prosser (2006), Pink (2006) and Wall and Higgins (2009) on analysing visual data for content and hermeneutically.

\section{Findings}

The findings presented here reflect the views of 20 international postgraduate students undertaking Masters degree in a Midlands University in England in 2010-2011, of whom 14 were Mainland Chinese students (Interviews 4-17, all female, shown below as MCNumber, e.g. MC6) and six were other international (i.e. non-UK) students from Japan (interview 18), Pakistan (interview 19), Iran (Interview 20), Ghana (interview 21), Cyprus (interview 22), India (interview 23) respectively, of whom only Interview 23 was male, (shown below as INumber, e.g. I18. Although the concept map data are not the primary focus of the present paper, they were subjected to independent analysis, and confirm the broadly positive relationship between the students and their environments expressed during interview.

The findings are presented in two main sections: 'Engaging with a strange culture', and 'Growing familiarity: Adapting to the culture'. The latter is divided into three subsections, 'Adapting to the City', 'Developing friendship networks' and 'Adapting to new regimes of academic work'. The views of all the international postgraduate students on these topics were largely similar.

\section{Engaging with a strange culture}

The international postgraduate students in this study gave many positive reasons for choosing to study in the city, including its multicultural nature: 
[It] is an international city because when I walked on the street I can see...many people are from other countries (MC7)

It is cheaper to live in [City] than Leeds, than London, and other cities (I19)

Others cited the perceived high academic status of the University (MC5; MC6; MC13). Some students indicated that their choice of City and University was linked to personal recommendation and situation:

A friend of mind is a graduate from [University] and she gave me some comments and suggestions (MC8)

My husband is already in [city] and when I started studying in Leeds I got problems because my husband [was here] (I19)

While this enthusiasm for their choice of study site appears to have helped them to engage positively with their work, initial unfamiliarity with cultural practices represented formidable challenges:

I was so shocked that it was 8 o'clock in the morning but I'd forgotten it was Sunday! Nobody was on the street [but] in China everywhere at any time you can see people. Then I realised people are living like a different lifestyle you know (MC13).

Further, the urban infrastructure was unfamiliar and seemed quaint to some international students:

The road, it's kind of narrow you know it's like two cars and that's it. But in China it's like four, at least four, normally six. I was told most of the British roads were like in the Victorian times (MC13)

Others were surprised at the multi-cultural and multi-ethnic nature of the city. For some, this was an isolating experience:

Firstly, I didn't know anyone, like complete strangers to me. And it took me quite a long time to adjust myself (MC 13)

However, some acknowledged that their insufficient command of English when they arrived made academic acculturation more difficult:

I think that maybe its better to learn and practice English more before we come here, it will decrease the difficulties with us coming here because when I first came here I found it very hard to understand the teachers and lecture[s] (MC11) 
Sometimes maybe we can't totally understand what the teacher or other students are saying (MC4)

This also made it more difficult for them to make friends with local people and understand local accents, an additional challenge to students only used to communicating in English in their language classes:

I think it's the accent. When I go out to market or club... it's quite difficult, someone will say speak English, like when you go to coffee shop (MC17)

A combination of unfamiliar social and linguistic practices led to some uncertainty amongst some international students about how to engage with local residents or home students:

Even though we know we have to communicate with foreigners ... natives are committed with natives.... We are happy to join, but it's hard for us to join and we don't know how to open the doors for us to join (MC16)

These feelings were exacerbated by the difficulties some students appeared to have in making contacts with local people:

I rent a house off site and it's far away from the city centre. I thought [getting private rented accommodation] may help improve my English and ma[ke] communication but actually I feel a little lonely because the neighbourhood is not ... (MC7)

[British students] are like quite far away although we meet them every day but it seems like there are no connections (MC13)

However, there were other international students who appeared to relish the challenge of the new:

When I just came to City I feel so much exciting and enjoy it. All the things are fresh and it's quite different from in China (MC16)

Within the University learning environment there were shocks, too. International students were surprised at the styles of learning that were expected of them, with which they were unfamiliar:

[Teaching here is] different to the styles in China. Not just delivering the knowledge to us (MC6)

We don't have tutors in Japan, (I18) 
I was confused in the beginning what I should do and I was a little bit demotivated. How I will do it, there are a lot of books ... I was unfamiliar with such studying style (I19)

International students were not used to independent learning, an approach that expects students to find out much of the information they need for their courses for themselves, albeit within a framework given to them by tutors. Some international students were surprised by the limited number of hours of lectures that they had:

I think the one year for the postgraduate is too short ... we don't have the time to learn the theory. I think the time of the lecture is too short. Its only one hour (MC 11)

Others were frustrated by the pressures on library resources:

Every time ... we prepare for our essays everyone books the same book ... and the day after tomorrow I receive an email, 'Please return it'... it's quite nervous for me (MC16)

As a result of the cultural conflicts they experienced in their early days in City and University some students said they had experienced homesickness:

You want to talk to others, maybe you want to make a call to your friends in China but because of time you can't (MC4)

\section{Growing familiarity: Adapting to the culture}

\section{Adapting to the City}

For many students, the 'shock of the new' (Chapdelaine and Alexitch 2004) diminished as they became more accustomed to the linguistic, social and academic customs of the site of their sojourn for postgraduate study. Becoming familiar with the rhythms of the City, for example, helped many international students have more comfortable lives:

[On] Saturday I see like quite a lot of people in the city centre, and I realised its different [from a quiet Sunday] (MC13)

In the UK after six o'clock pm most of the shops will close and you can't go shopping any more. [people enjoy] get together with family (MC16)

Its not as big as the city I used to live in but I think it is clean and everything is tidy (MC11)

Finding foods with which international students were familiar in their own countries, one of the benefits of a multicultural environment, provide another sense of security and familiarity: 
I am OK because I cook myself and I have Chinese food and I also buy some sausage in the Asia market. I'm independent really (MC4)

There are a lot of shops, market ... Indian things [are] easily available (I19)

A third aspect was discovering local entertainments and activities. Some students found this to be somewhat underwhelming:

I find it kind of boring, because there are less entertainment. Except for talking with my friends and travel. Simple life for me here. I study, sleeping, talking and travelling ... there are so many [more] entertainments in China (MC16)

However, other international students painted a more positive picture, which partly reflected a sense of the City as being on a 'manageable' scale:

I think [the City] nice and quiet. Not so big. It's OK. A lot of times... with my friends, go to dinner or... shopping, or karaoke...I have several close friends (MC15)

It gives me a chance to know different countries culture and the transitional (?) things (MC10)

You might felt some culture shock and some homesick sometimes but you can find some...very...interesting social activities like join a dancing club or some academic study clubs (MC8)

Contacts with local people, who were perceived as approachable, helped this growing familiarity:

British people are quite polite. The first day I came here I lost my way and ... help[ed] me to find the way (MC9)

I actually I like [City] very much because the people here is very kind, they are friendly (MC10)

At the core of international students' adaptation to living and working in a strange city was developing a network of friends. These often involved those who shared a linguistic and/or cultural background:

Well the good thing about [there being] lots of Chinese students I can make lots of

Chinese friends and we have parties, lots of talk, and drinking and stuff (MC13) However, getting stuck in a linguistic 'ghetto' with their co-linguists was also seen as a barrier to acculturation: 
Because there are so many Chinese students and when I see them I not feel so exciting... because it's just normal, like in China (MC15)

I don't want to always stay with... the students from my community... I want to experience British culture and life. I like British culture in my undergraduate studies (MC17)

Maintaining a balance between the two positions might therefore be seen as a 'socially healthy' position to aspire to.

\section{Developing friendship networks}

Whatever their predisposition, students in the study identified three main domains for developing their friendship networks: accommodation, Students' Union, and study practices. Not surprisingly, their accommodation represented a key social site:

Because I don't have friends that we come together here, so I live in [University supplied accommodation] so I've made some friends from the ... flatmates (MC11)

Private rented flats and houses gave a similar opportunity, although students often chose to lodge with co-linguists:

I'm renting a house ... I like it very much ...I live with friends I met here. The furniture is new and the house is clean (MC5)

I rent a house outside the campus and I share with my classmates. I enjoy the process, and we talk about our course ... our lives (MC6)

Another domain was the Students' Union of the University, which offered a range of activities and thus opportunities for meeting people:

The Students' Union is doing an amazing job. They always lend a hand to whatever problem (MC6)

Last week I went to Latin dance class... in Student Union ... nothing else (MC14).

When we join the social activities, there are a lot of parties, and I have been there several times (MC16)

For some students this included the range of sports facilities available:

Most of my classmates play there and we can do some physical work. it's a gym. Yoga is quite important to me. We take a card and... I can go there every day (MC16) 
The third domain for developing friendships was international students' academic work the programme of study in which they were engaged:

It is my first time so far away from home so [...] and I like my classmates, they are all very kind, like my family (MC9)

Some approaches to pedagogy, such as group work, with which they had been unfamiliar when studying in previous institutions, helped international students to develop friendships as well as a new, collaborative approach to learning:

Group work is a good way for us to learn how to collaborate with other peoples and it's also a good way to see other people's viewpoint and ...to learn from each other (MC10)

Other sites in the University, where the students went for private study, also helped to develop friendships. In particular the University library - and the coffee bar within it acted as a focus not only for independent learning but also for socialisation:

I think what most impressed me was the library, yeah, it's quite nice. It's very comfortable here for study. It's very easy to find the resources, books (MC4)

We go to the library together. After maybe two weeks I meet some friends (MC13)

\section{Adapting to new regimes of academic work}

The support which tutors were said to give international students helped them to understand learning processes with which they were unfamiliar:

[Tutors] are just like a guide, giving me some suggestions and directions. So I like this style of teaching (MC6)

The tutors ... help us a lot in terms of assignments (I18) A major element of this was the time which many tutors were reported to devote to their students:

So I'm really appreciative. In China, most of the time we communicate with teachers in class. There's seldom office hours [tutorials] for Chinese teachers (MC16)

I was impressed with the tutors here because we don't have personal tutors from the background I came (I22)

In part this seemed linked to the perceived enthusiasm and knowledge which many tutors had of their subjects: 
The support is very good you know, if I don't understand anything I just...give someone [tutor] an email and I will get a response very quickly (MC13)

I find I have some problems with my essay my tutor will always tell me don't worry mostly we can find a way to address that (MC4)

Adapting to the new culture was linked to the enthusiasm which the international students developed for their courses and for new ways of learning:

Most of the time I think I'm enjoying the time here and enjoying my course (MC7).

And the course here is worth to learn. The facilities at the University is [sic] very good. The library is very good (MC10)

It was also linked to the international students becoming increasingly competent in English and able to understand what was expected of them. Some international students noted that early in their courses:

Sometimes maybe we can't totally understand what the teacher or other students are saying (MC4).

So I needed to spend much time on reading. When I read some books I found some information, some words I couldn't understand so it's difficult for me learning here (MC6)

\section{Discussion and Conclusions}

The findings from this small study of predominantly female international postgraduate students suggests that making sense of their experiences of studying in a Western university in England is complex. Some of that complexity is related to the students' histories. For some, coming to the City and University represented the first time they had visited the West. Others had a clearer understanding of what was involved in being an international student in a particular environment, perhaps because they were already in Britain or had made use of the extensive information available on the internet or advice given by friends and family. As their initial shock at the unfamiliar ways of living and working which they encountered moderated, students seemed to gain an appreciation of both City and University culture and practice. However, initial senses of culture shock (Chapdelaine and Alexitch 2004; Wu and Hammond 2011) seemed to apply as much to 
living in the City as to learning in the University, contesting the work of Gu et al. $(2010,19)$ that initial sense of shock largely apply to academic processes. Regardless of their initial understandings, however, participants in this study seemed very determined to be successful in their work and to overcome the difficulties they perceived when they first arrived in City and University.

The students' command of English was, perhaps, a major factor in their responses to their early weeks in the City and University. The unfamiliar linguistic context, raised the level of challenge for both their social and educational interactions (Mulligan and Kirkpatrick 2000; Zhang and Mi 2010). Copland and Garton (2011) suggested that language proficiency is key to both academic and social integration. Several participants in this study admitted that they struggled to understand written and oral work and to express themselves in a variety of contexts in the early stages of their courses and their sojourn in the City. This may be at least as convincing an explanation of the perceived passivity of East Asian students, to which Barron et al. (2010) allude, as cultural attitudes of respect for teachers which they brought with them.

It is, however, unfair to consider that international students were uncritical of their experiences, whether in the University or in the City, as Barron et al. (2010) suggested. More accurately, some processes, such as group work or independent learning, were unfamiliar to the international students. So the students were uncertain how to enact these processes which Gonçalves (2011) thought particularly challenging for East Asian students. What the students in this study needed was to understand how to be successful in what to them were strange processes. So they were very grateful to receive extensive support from approachable tutors with this. In this they were aided by the University infrastructure, especially the library, which seems to have given the students a pleasant and sociable place to work. What the students also valued were collaborative approaches to learning and the availability of a range of social opportunities. Initially the University's Students Union which gave students a site in which to socialise and make friends, much as Dixon et al. (2007) noted. Later in the City as they discovered what it had to offer and where they could socialise there. Although in this study many social encounters appeared not to lead to intercultural activities by the international students but to the construction of friendship groups of people with the same first language, some students also enjoyed engaging with local people and students. 
The international students in this study, like those studied by Pritchard and Skinner (2002) experienced considerable social tensions in the early days of their sojourn in City and University. These included feelings of isolation or loneliness because of unfamiliar social conventions/mores. However, they reported finding solutions to these tensions through building up networks of friends, often with their co-linguists, through their courses and accommodation, as well as through familiarising themselves with ways of living in the City. Within the University their tutors appear to have played a major part in facilitating their familiarisation, echoing the work of Bourdieu, Passeron and St Martin (1994). None the less several of the students in this study referred to their experiences of adapting to living and learning in a strange culture as one of culture shock (Chapdelaine and Alexitch 2004, Wu and Hammond 2011). One participant even commented that he/she had written an essay on the topic and noted the symptoms fitted her/his own experience closely.

The complexity of students' experiences found in this study questions the U-curve hypothesis of Lysgaard (1995). Although this study shows evidence of her stages of culture shock and adjustment, several students in this study never appeared to have a happy honeymoon period at the start of their sojourn in England. Others, perhaps, never felt they achieved mastery of living in a strange culture, although they reconstructed themselves as learners living in a Western culture sufficiently well to be confident of academic success, some even hoping to undertake Doctoral studies after the end of the Masters level courses.

\section{Acknowledgements}

\section{Research Assistants:}

Gareth Lewis, Paula Cummings and other postgraduate students on the Masters degree in International Education who acted in this capacity

\section{Funding:}

This work was supported by the College of Social Sciences, the University [name witheld for ethical reasons]. 


\section{Notes on Contributors}

Hugh Busher has a PhD in the micro-politics of schools and is a Senior Lecturer in the School of Education, University of Leicester. He researches into critical perspectives on people, power and culture in education-based communities, including representations of students' and teachers' voices, and hybrid learning communities. He teaches on Masters and Doctoral programmes. His current funded research project, with Dr Nalita James, is on widening participation in Higher Education: marginalised adult students' shifting learning identities on Access to HE courses. Recent publications focus on: student perspectives on learning; visual ethnography; teachers' identities; liminality; power in communities.

[If you need to shorten my bio, then please remove the yellow highlighted text]

Gareth Lewis*

Chris Comber*

** I suggest we use the ones that you used before, Gareth, when you first submitted this article - although obviously modify yours if you wish

\section{References}

Barron, P. (2003) Issues surrounding Asian students studying hospitality management in Australia: A literature review regarding the paradox of the Asian learner. Journal of Teaching in Travel and Tourism 3(1) 23-45.

Barron, P. Gourlay, L. and Gannon-Leary, P. (2010) International students in the higher education classroom : initial findings from staff at two post - 92 universities in the UK. Journal of Further and Higher Education, 34(4) 37-41.

Bhabha, H. (1994) The location of culture. London: Routledge

Borthwick, A. (2011) Children's perceptions of, and attitudes towards, their mathematics lessons. In C. Smith, (Ed.) Proceedings of the British Society for Research into Learning Mathematics 31(1) 37- 42

Bourdieu, P. Passeron,J-C. De Saint Martin, M. (1994) Academic Discourse, Linguistic Misunderstanding and Professorial Power Cambridge: Polity Press

Busher, H. (2005a) Being a middle leader: exploring professional identities. School Leadership and Management, 25(1) 137-154

Busher, H. (2005b) The Project of the other: Developing inclusive learning communities in schools. Oxford Review of Education, 31(3) 459-477

Chapdelaine, R.E. and Alexitch, L.R (2004) Social Skills Difficulty: Model of Culture Shock for International Graduate Students Journal of College Student Development, 45 (2) 167-184 Chen, W. (2006). Intercultural friendship from the perspectives of East Asian international students. China Media Research, 2 (1) 43-58.

Copland, F. and Garton, S. (2011) "I felt that I do live in the UK now": international students' self-reports of their English language speaking experiences on a pre-sessional programme. Language and Education, 25(3) 241-255. 
Dixon, J., Durrheim, K. and Tredoux, C. (2007) Intergroup contact and attitudes toward the principle and practice of racial equality. Psychological Science, 18(10) 867-872.

Deardorff, D. (2006) Identification and Assessment of Intercultural Competence as a Student Outcome of Internationalization. Journal of Studies in International Education, 10(3) 241-266

Giddens (1991) Modernity and Self-Identity: Self and Society in the Late Modern Age. Stanford, CA: Stanford University Press

Goodson, I. F., and U., Numan. (2002) Teacher's Life Worlds, Agency and Policy Contexts, Teachers and Teaching 8: 269-277

Gonçalves, S. (2011) Intangible culture, cooperation and intercultural dialogue among university students. Intercultural Education, 22(1) 3-95.

La Brack, B. (2002) Book Review: The psychology of culture shock, 2nd edition Colleen Ward, Stephen Bochner and Adrian Furnham; Routledge, Philadelphia, PA, 2001, 384pp International Journal of Intercultural Relations 26: 595-607

Lei, B. (2010) An investigation of East-Asian international students' perception of collaborative learning within social sciences departments in England. Unpublished MA Dissertation, School of Education, University of Leicester, Leicester, UK

Gu, Q., Schweisfurth, M. and Day, C. (2010) Learning and growing in a 'foreign' context: intercultural experiences of international students. Compare: A Journal of Comparative and International Education, 40 (1) 7-23

Li, P. (2011) A case study of the issues and challenges of Chinese Taught Postgraduate Students' transition at a University in the Midlands of England. unpublished MA Dissertation, School of Education, University of Leicester, Leicester, UK

Lysgaard, S. (1955) Adjustment in a foreign society: Norwegian Fulbright grantees visiting the United States. International Social Science Bulletin 7(1), 45-51.

Mulligan, D., \& Kirkpatrick, A. (2000). How much do they understand: Lecturers, students and comprehension. Higher Education Research and Development 19 (3) 311335.

Pink, S. (2001) Doing visual ethnography. London: Sage publications

Pritchard, R. and Skinner, B. (2002) Cross-cultural partnerships between home and international students. Journal of Studies in International Education 6(4), 323-54.

Prosser, J. (2006) Image-based research: a sourcebook for qualitative researchers. London: RoutledgeFalmer

Sam, D. (2001). Satisfaction with life among international students: An exploratory study. Social Indicators Research, 53(3) 315-337.

Summers, M. \& Volet, S. E. (2008). Students' attitudes towards culturally mixed groups on international campuses: Impact of participation in diverse and non-diverse groups. Studies in Higher Education, 33(4) 357-370.

Vygotsky, L.S. (1978) Mind in society. Cambridge, MA: Harvard University Press. Wall, K. \& Higgins, S. (2009) Pupils' views of Templates: A visual method for investigating children's thinking, ESRC Seminar, Leicester University, Jan 2009 Webb, N., and Palincsar. A .(1996) Small group processes. In The handbook of educational psychology, ed. D. Berliner and R. Calfee, 841-73. Washington, DC: American Educational Research Association.

$\mathrm{Wu}, \mathrm{W}$. and Hammond, M (2011) Challenges of university adjustment in the UK: a study of East Asian Master's degree students, Journal of Further and Higher Education, 35(3) 423-438

Zhang, Y. and Mi, Y. (2010) Another look at the language difficulties of international students, Journal of Studies in International Education 14(4) 371-388. 
Zhen, Z. (2009) A case study of the cross-cultural adaptation experiences of Chinese postgraduate students in Britain: are there similarities or differences between mainland Chinese postgraduate students and Hong Kong Chinese postgraduate students? unpublished MA Dissertation, School of Education, University of Leicester, Leicester, UK 